Response to Commentaries on: Inflexibly Enacted Traditional Masculinity Norms (IE-TMNs) and Their Impact on Adolescent and Young Adult Depression: The Hybrid Case Study of Tommy"

\title{
Revisiting "Tommy": Further Considerations of Best Practices for Addressing Inflexibly Enacted Traditional Masculinity Norms (IE-TMNs) with Boys and Men in Therapy
}

\author{
CHRISTOPHER DEWEY ${ }^{\mathrm{a}, \mathrm{b}}$ \\ ${ }^{a}$ Providence College Personal Counseling Center, Providence, Rhode Island \\ ${ }^{\mathrm{b}}$ Correspondence regarding this article should be sent to: Christopher Dewey, Providence College Personal \\ Counseling Center, 1 Cunningham Square, Providence, RI 02918 \\ Email: deweyc24@gmail.com
}

\begin{abstract}
In this article, I respond to the thoughtful commentaries and critiques offered by James Mahalik (2020), Ethan Hoffman and Michael Addis (2020), and Ginelle Wolfe and Ron Levant (2020) on my hybrid case study of "Tommy" (Dewey, 2020), a college freshman exhibiting symptoms of depression, alcohol use concerns, and inflexibly enacted traditional masculinity norms (IETMNs) during a time of difficult transitions and loss in his life. These commentaries have reaffirmed many of my beliefs about best practices for working with boys and men in therapy, while also expanding my knowledge of the psychology of men and masculinities (PMM) and introducing me to conceptual frameworks and therapeutic goals not directly explored in my original case study. Additionally, these three commentaries underscored areas of particular importance that I would like to discuss in further detail, including, (a) Hoffman and Addis's differentiation between reconstructing and deconstructing masculinity as treatment aims when working with boys and men in therapy; (b) the benefits of employing Interpersonal Theory to better conceptualize presenting concerns related to traditional masculinity norms as highlighted by Mahalik; (c) constructive criticism from Wolfe and Levant and from Addis and Hoffman about the need for closer examination of social justice themes that arise when addressing masculinity in treatment; and (d) concerns about the generalizability of the case study raised by all three commentaries.
\end{abstract}

Key words: masculinity; traditional masculinity norms; inflexibly enacted traditional masculinity norms; depression; substance use; alcohol; gender norms; cognitive restructuring; behavioral activation; motivational interviewing; harm reduction; case study; hybrid case study

\section{INTRODUCTION}

I designed the Case of "Tommy" (Dewey, 2020) to illustrate how clinical concerns related to inflexibly enacted traditional masculinity norms (IE-TMNs) might arise when working with adolescent and young adult males in treatment. I chose to focus on a case that took place in a college counseling center due to my numerous experiences of having served in such a setting, 
C. Dewey

Pragmatic Case Studies in Psychotherapy, http://pcsp.libraries.rutgers.edu

Volume 16, Module 3, Article 5, pp. 330-338, 12-28-20 [copyright by author]

and because I recognized how working with clients transitioning from adolescence into adulthood provided a unique developmental period during which masculinity-related issues could be addressed in a meaningful way. For many students, college is the first time that they are able to live on their own and function with relative independence and autonomy, as well as limited supervision. While some thrive in these conditions, others struggle with the transition and choose to seek therapy for the first time in their lives, giving them a chance to examine beliefs, values, and goals that they may have never consciously considered before.

It was important for me to discuss how IE-TMNs tend to arise in treatment more as a byproduct of other presenting concerns rather than being the primary issue that brings the client into treatment. While it is unlikely that a college-aged client will explicitly attend treatment to address their struggles with their masculine identity, it is not uncommon for these themes to naturally arise through exploration of a client's depression, anxiety, trauma history, substance use issues, or relational difficulties. In Tommy's case, his alcohol abuse, depression, and fractured relationships were all interconnected. His beliefs about masculinity ran under the surface of these presenting concerns, covertly guiding his behavior and limiting the ways in which he expressed emotion and sought help from others.

As a recent doctoral clinical psychology graduate, it has been humbling and very gratifying to receive feedback on the Case of Tommy through the three commentaries, whose authors include Mahalik, Addis, and Levant, prominent experts in the field of the psychology of men and masculinities (PMM). These authors were deeply involved in the development of the seminal APA Guidelines for Psychological Practice with Boys and Men (APA, 2018), giving their words particular weight and gravitas. Such positive responses and constructive critiques from these figures have broadened my understanding of the themes highlighted in my case study and reaffirmed my desire to make this subject a central focus of my future clinical work. It was a particular honor to receive feedback from Mahalik, the professor who originally introduced me to this area of study during my master's program at Boston College.

\section{RECONSTRUCTING VS. DECONSTRUCTING MASCULINITY}

Throughout my work with Tommy, I attempted to help him redefine his masculinity in order to alleviate the pressure that he felt to strictly adhere to traditional masculinity norms. This included exploring his values and discussing his long-term hopes and goals for the future. By reconstructing his masculinity, I hoped that he could develop a healthier, more flexible relationship with his gender identity and act in greater accordance with his values. During his treatment, terms such a "positive masculinity" and "healthy masculinity" were employed to broaden his beliefs about what a man could be and how he could still identify as male while performing behaviors that would be more beneficial to himself and those around him.

In their commentary on the case, Hoffman and Addis (2020) raise the question of whether clinicians should strive to help boys and men reconstruct masculinity in treatment or if it would be more beneficial to focus on deconstructing masculinity and making that aspect of identity less salient for the client. Wolfe and Levant (2020) also echo these sentiments and voice their concerns over affixing the terms "positive" and "healthy" to masculinity, stating that a 
C. Dewey

Pragmatic Case Studies in Psychotherapy, http://pcsp.libraries.rutgers.edu

Volume 16, Module 3, Article 5, pp. 330-338, 12-28-20 [copyright by author]

multidecade consensus of PMM research finds that masculinity is harmful no matter how we choose to reinterpret or soften its definition.

The idea of dispensing with both "positive masculinity" or "healthy masculinity" and reconstructing masculinity and making it less central to the client's identity is an attractive prospect. Indeed, it is important to help our male clients consider a greater range of emotions and attributes that are not necessarily linked to their gender identity. Hoffman and Addis (2020) highlight how one could use Acceptance and Commitment Therapy to assist in this deconstruction process (Hayes et al., 2012). Through this lens, masculinity could be viewed as a "process goal" that helps the client achieve "outcome goals." In this case, masculinity norms are a means to an end and it is incumbent on the clinician to understand the functional goals of why they are being enacted. By helping the client identify their values and goals and underscoring how IE-TMNs are hindering these aspirations, the therapist makes masculinity less central to the client's understanding of himself and how he makes progress in his life. In short, masculinity is no longer viewed as the toolbox that they must use in order to succeed.

Based on my clinical experience, I would be curious to see if clients who are particularly entrenched in the ideology of traditional masculinity norms might need to first reconstruct their beliefs about masculinity before they are able to tolerate the notion of deconstructing it altogether. In such cases, the reconstruction or redefining process could be conceptualized as more of a stepping-stone than an end goal for such individuals. This gives the client the opportunity to differentiate between healthy vs. unhealthy values, norms, and attributes that they were taught and, over time, view the positive attributes as independent of being masculine. While this may not be the ideal outcome, it could be viewed as a practical short-term goal in a stepwise process for male clients who still view masculinity as particularly central to their identity and may rebuff help if they perceive, correctly or incorrectly, that masculinity is being depicted as inherently problematic.

Both of these commentaries raise valid questions about the potential harm that could stem from the use of the terms "positive masculinity" and "healthy masculinity." Attributes that are evoked as positive or healthy in this case include independence, courage, and strength. These commentaries highlight that such attributes are by no means unique to masculinity and suggest that by equating them with positive or healthy masculinity, the clinician might be implying that the client has to include them in their identity in order to be healthy. Further, it might send the message that being masculine is still the end goal. They raise the question of whether linking these attributes to masculinity is dismissive towards individuals with different gender identities.

I would argue that, while values such as courage are not specific or essential to masculinity, they are certainly qualities that many associate with traditional masculinity. Allowing the client to select attitudes, attributes, and norms from this ideology that are beneficial when flexibly enacted should not be viewed as an attempt to re-constrain them to a newer, more palatable gender straitjacket. Conversely, I think it would be particularly important to emphasize that women, non-binary individuals, and transgender individuals, for instance, can also be courageous and that a quality like courage, while associated with the traditional understanding of masculinity, is not specific to that particular gender identity. By the same token, I would encourage my male clients to grow more comfortable adopting certain qualities traditionally 
associated with femininity, such as empathy and vulnerability, and exploring how these qualities could help them reach their outcome goals. Such a stance aims to steer clear of claims of gender essentialism by illustrating that norms that are traditionally linked to particular gender ideologies are not exclusive to them.

The model of Critical Positive Masculinity partially addresses some of these critiques, suggesting that there is great value in identifying strengths thought of as traditionally masculine and exploring how such strengths can serve to increase the health and well-being of the individual, while also emphasizing equality to rather than superiority over those of other gender identities (Lomas, 2013). Instead of recommitting to harmful traditional norms, boys and men should be encouraged to resist traditional norms that are harmful to themselves and others when inflexibly enacted and re-interpret other masculine norms in such a way that benefits themselves, their social network, and their communities. This theory does not deny the problematic aspects of masculinity nor does it dismiss the ways in which it has been used to subjugate other groups. Rather, it emphasizes the nuances and complexities of men and masculinities and avoids surfacelevel discourse that unconditionally equates masculinity with problematic behavior (e.g., using terms such as "toxic masculinity"), recognizing that such attitudes may only serve to repel boys and men from exploring their masculine identities and to further solidify them in hegemonic worldviews. By exploring positive aspects of masculinity and mindfully recognizing the many harms caused by traditional masculinity, one is encouraged to make change in their life, challenge hegemonic structures, and strive for greater gender equality.

\section{INTERPERSONAL THEORY}

I have always prioritized being an integrationist in my clinical work and believe that there is great value in being able to competently employ different theoretical orientations and conceptual frameworks. This flexibility has allowed me to recognize the individual differences between my clients and utilize a variety of evidence-based interventions according to their unique needs. Mahalik (2020) rightfully offers Leary's (1957) model of Interpersonal Psychotherapy and Kiesler's (1983) related model of Interpersonal Theory as frameworks to better understand why individuals enact IE-TMNs and how to address such issues in treatment.

According to Kiesler's model of Interpersonal Theory, clients, such as Tommy, will often exhibit a rigid and exaggerated version of their masculinity identity (i.e., IE-TMNs) when under conditions that threaten their sense of self. In turn, their behavior also pulls for an equally restrictive and inflexible relationship from others around them. In the case of Tommy, his desire to have control over his emotions and to be self-reliant was not inherently problematic. As Mahalik notes, such qualities can be admirable when they are only parts of an individual's behavioral and emotional repertoire, but they become more troublesome when the individual is unable to consider other means of relating to themselves and others. For Tommy, his breakup and academic difficulties were significant threats to his self-esteem and identity. His subsequent behaviors can be understood as an attempt to narrow the gap between his ideal masculine self and his actual masculine self (Wolfe \& Levant, 2020; Pleck, 1995). 
C. Dewey

Pragmatic Case Studies in Psychotherapy, http://pcsp.libraries.rutgers.edu

Volume 16, Module 3, Article 5, pp. 330-338, 12-28-20 [copyright by author]

Although I am not intimately familiar with the interpersonal models offered by Mahalik, I appreciate their focus on conceptualizing masculinity as an interactive and transactional process where norms are constructed and perpetuated through repeated social interactions over time. Tommy's psychopathology can be viewed as taking place due in part to repetitive and maladaptive cycles of interpersonal behavior in which he tries to regain the self-esteem and outward persona that allowed him to thrive in high school. However, his pursuit of short-term outcomes that he hopes will mitigate his distress (e.g., drinking alcohol and hookups) only serves to facilitate long-term damage to his relationships and further cement constricting patterns of relatedness to others. While I did not consciously use Interpersonal Theory in my work with Tommy, the goals were similar in regard to examining and changing interpersonal behaviors and exploring thoughts about one's self-schema as they relate to masculinity. I am fortunate to now have an additional framework for understanding clinical concerns related to IE-TMNs.

\section{SOCIAL JUSTICE CONSIDERATIONS}

While discussing concepts like IE-TMNs in therapy with boys and men, it is essential that clinicians explore the variety of ways in which such beliefs and behaviors negatively impact the health of the individual client (Addis \& Mahalik, 2003: Courtenay, 2000; Mahalik et al., 2007). Simultaneously, we must also underscore how these masculine worldviews and attitudes can cause harm to the client's friends and family, as well as minority groups and society at large (Mankowski \& Maton, 2010). Enactment of traditionally masculine attributes has been found to be associated with greater intimate partner violence, homicide, environmental degradation, unemployment, and aggression factors (Krahé \& Fenske, 2002). Thus, addressing masculinity in treatment should not only be viewed as an attempt to heal clients, but also as an effort to shed light on how the clients' beliefs and behaviors might be eroding the wellbeing of the communities in which they exist and hinder efforts to create conditions that allow for greater equality between different groups.

These social justice considerations were not as thoroughly explored in my case study as they should have been. While I utilized Bronfenbrenner's Ecological Systems Theory (1979) to describe how Tommy received messages about masculinity from different levels of his community, I failed to employ this framework to more fully explore how Tommy's attitudes and actions could have been impacting those around him, damaging aspects of his community, or perpetuating patriarchal attitudes and inequality. While I stressed that his rigid enactment of masculinity norms was more of a problem than the norms themselves, I should have also emphasized that certain traditional masculinity norms are inherently pathological because of the ways that they harm others and perpetuate misogyny, racism, and other societal power imbalances (Mahalik, 2020).

For example, I could have inquired if Tommy was reluctant to relinquish certain IETMNs because they allowed him to feel empowered and superior to people from other backgrounds. It may have been prudent to explore the extent to which he did or did not experience the power and privilege that is often attached to being a young, Caucasian, cisgender, able-bodied, and heterosexual male in our society (Wolfe \& Levant, 2020). Though it is unlikely that Tommy would have consciously identified with such sentiments and would have mounted a strong protestation at such possibilities, having a greater discussion about how IE-TMNs 
contribute to societal inequality and providing additional psychoeducation could have served to broaden his worldview and increase his awareness of how he was potentially harming those around him. For instance, I could have highlighted how men who hold traditional beliefs about masculinity and feel that their masculinity is being threatened are more likely to accept instances in which women or gay men experience inequality or deny that inequality even exists (Weaver \& Vescio, 2015).

In particular, I do not believe that I took enough time to explore and address Tommy's apparent internalized misogyny. Although he was not one to express outright sexist beliefs or use derogatory terms when describing his female friends and family members, his actions indicated a proclivity toward objectifying women and viewing them as prizes and a means to his own selfgratification. This is reflected in his use of social media to explore all of his possible hookup options and most prominently in the incident in which he essentially stalked a female classmate back to her dorm and demanded to be let into her room because he seemingly felt entitled to a sexual encounter. This egregious incident deserved greater attention and should have been a greater focus of both why his drinking was being viewed as problematic and how dangerous IETMNs can be if not recognized and scrutinized.

\section{GENERALIZABILITY OF THE CASE}

All three of the commentaries have rightfully highlighted issues of generalizability inherent to the case of Tommy. Tommy represents my experiences of working with Caucasian, heterosexual, cisgender, and able-bodied adolescents and young men. As such, the conclusions drawn by this case study may not be generalizable to clients who are from different backgrounds. While there is evidence to suggest that there are some similarities in how traditional masculinity is defined across different cultural groups, such as preoccupation with therapy and hesitancy to seek help (Reigeluth \& Addis, 2010), enactments of traditional masculinity norms and how these behaviors and attitudes are perceived by others has been found to vary across cultures (Lease et al., 2013).

On reflection, one of the reasons why it was a fairly streamlined process to create the hybridized character of Tommy was because so many of my experiences in college counseling centers included working with Caucasian male clients who came from middle- to upper-class socioeconomic backgrounds. I was able to readily identify similarities across my male clients because they shared a number of common experiences and struggles. While my case study may be helpful for clinicians who work with clients similar to Tommy, it may prove less applicable when serving clients from other backgrounds. This shortcoming is representative of a myriad of needs. First and foremost, future PMM research needs to make a greater effort to spotlight minority groups in their research. Additionally, on top of increasing minority representation on college campuses, university counseling centers need to increase outreach efforts that target more vulnerable groups and increase their engagement in services. 


\section{LARGER SOCIETAL IMPLICATIONS}

The discussion over the detrimental impact of traditional masculinity norms is no longer relegated to the study of PMM and has entered the realm of popular culture and media discourse (Itulua-Abumere, 2013). In particular, debates over the harms or merits of masculinity are now fairly commonplace in the U.S. political sphere. Some have suggested that the 2020 presidential election was partially a contest between two different codes of masculinity, with Donald Trump representing a "confined" and juvenile masculinity and Joe Biden representing a "liberating," more fluid idea of masculinity (Adams \& Frauenheim, 2020). While Biden is not above falling back on traditional masculinity norms (e.g., challenging opponents to push-up contests when his physical strength is criticized), the compassion and warmth that he exhibits is a notable departure from Trump. In a recent interview, Barack Obama highlighted the discrepancy between traditional masculinity and the model of masculinity that some have found in Trump, saying:

The code of masculinity that I grew up with that harkens back to the ' 30 s and ' 40 s and before that - there's a notion that a man is true to his word, that he takes responsibility, that he doesn't complain, that he isn't a bully; in fact he defends the vulnerable against bullies. And so even if you are someone who is annoyed by wokeness and political correctness and wants men to be men again and is tired about everyone complaining about the patriarchy, I thought that the model wouldn't be Richie Rich - the complaining, lying, doesn't-takeresponsibility-for-anything type of figure (Goldberg, 2020).

For some, it appears that the outcry about preserving traditional masculinity is less about maintaining virtuous ideals that contribute to stronger communities and more of a battle cry against "political correctness," progressivism, and efforts to dismantle structures that perpetuate power imbalances that harm vulnerable groups. Internet provocateurs looking to make a dollar from outrage and controversy, such as Ben Shapiro, have latched onto this movement and have adopted the defense of masculinity as one of their core causes (Evans, 2020). These critics, such as Shapiro, are often not as outwardly stoic, athletic, or rugged, for instance, as one might expect from people so set on saving traditional masculinity and its associated attributes. Instead, intended or not, their defense of this worldview appears to be more about safeguarding rigid gender roles and social structures that secure their standing in society at the expense of others.

With masculinity now explicitly part of the national conversation and partisan divisions, it is more important than ever to consider the larger societal implications that are at play when our clients present with IE-TMNs. As the field of the PMM moves forward, it is imperative that added attention be dedicated towards exploring how issues of masculinity impact those of different gender identities, racial and ethnic backgrounds, sexual orientations, levels of ablebodiedness, political persuasions, and other salient identity characteristics. I believe there remains great value in studying cases like Tommy's and understanding how addressing IETMNs with such privileged clients may serve as an opportunity to quell dangerous attitudes that perpetuate inequality in our society. At the same time, we cannot concurrently neglect efforts to better understand the experiences of boys and men from different backgrounds. Otherwise, we run the risk of violating the same egalitarian goals that we champion when we attempt to address IE-TMNs in treatment. 


\section{REFERENCES}

Adams E., \& Frauenheim E. (2020, October 26). Manhood on the ballot: Trump's selfabsorbed bullying vs. Biden's compassion and humility. USA Today. https://www.usatoday.com/story/opinion/2020/10/26/trump-bullying-biden-compassionmanhood-election-2020-column/3717416001/

Addis, M.E., \& Mahalik, J.R. (2003). Men, masculinity, and the contexts of help-seeking. American Psychologist, 58(1), 5-14.

American Psychological Association, Boys and Men Guidelines Group. (2018). APA guidelines for psychological practice with boys and men. Retrieved from https://www.apa.org/about/policy/boys-men-practice-guidelines.pdf

Bronfenbrenner, U. (1979). The ecology of human development. Cambridge: Harvard University Press.

Courtenay, W.H. (2000). Constructions of masculinity and their influence on men's well-being: A theory of gender and health. Social Science \& Medicine, 50(10), 1385-1401.

Dewey, C. (2020). Inflexibly enacted traditional masculinity norms (IE-TMNs) and their impact on adolescent and young adult depression: The hybrid case study of "Tommy." Pragmatic Case Studies in Psychotherapy, 16 (3), Article 1, 237-304. Available: http://pcsp.libraries.rutgers.edu/

Evans, J. (2020, November 17). Harry Styles in a dress isn't an attack on masculinity, no matter what Ben Shapiro and Candace Owens say. Esquire. https://www.esquire.com/style/mens-fashion/a34700057/ben-shapiro-harry-styles-voguecover-dress-controversy/

Goldberg, J. (2020, November 16). Why Obama fears for our democracy. The Atlantic. https://www.theatlantic.com/ideas/archive/2020/11/why-obama-fears-for-ourdemocracy/617087/

Hayes, S.C., Strosahl, K.D., \& Wilson, K.G. (2012). Acceptance and commitment therapy: The process and practice of mindful change $\left(2^{\text {nd }} \mathrm{ed}\right.$.). New York, NY: Guildford Press.

Hoffman, E., \& Addis, M.E. (2020). Reconstructing and/or deconstructing masculinity: A commentary on the case of "Tommy." Pragmatic Case Studies in Psychotherapy, 16 (3), Article 3, 312-319. Available: http://pcsp.libraries.rutgers.edu/

Itulua-Abumere, F. (2013). Understanding men and masculinity in society. Open Journal of Social Science Research, 1(2), 42-45.

Kiesler, D. J. (1983). The 1982 interpersonal circle: A taxonomy for complementarity in human transactions. Psychological Review, 90, 185-214.

Krahé, B., \& Fenske, I. (2002). Predicting aggressive driving behavior: The role of macho personality, age, and power of car. Aggressive Behavior, 28, 21-29.

Leary, T. (1957). Interpersonal diagnosis of personality. New York: Ronald.

Lease, S. H., Montes, S. H., Baggett, L. R., Sawyer, R. J., Fleming-Norwood, K. M., Hampton, A. B., Ovrebo, E., Çiftçi, A., \& Boyraz, G. (2013). A cross-cultural exploration of masculinity and relationships in men from Turkey, Norway, and the United States. Journal of Cross-Cultural Psychology, 44(1), 84-105

Lomas, T. (2013). Critical positive masculinity. Masculinities and Social Change, 2(2), 167-193. 
Mahalik, J.R., Burns, S.M., \& Syzdek, M. (2007). Masculinity and perceived normative health behaviors as predictors of men's health behaviors. Social Science \& Medicine, 64(11), 2201-2209.

Mahalik, J.R. (2020). Understanding the role of inflexibly enacted masculinity norms in therapy: A commentary on the case of "Tommy." Pragmatic Case Studies in Psychotherapy, 16 (3), Article 2, 305-311. Available: http://pcsp.libraries.rutgers.edu/

Mankowski, E.S., \& Maton, K. I. (2010). A community psychology review of men and masculinity: Historical and conceptual review. American Journal of Community Psychology, 45, 73-86.

Weaver, K.S., \& Vescio, T.K. (2015). The justification of social inequality in response to masculinity threats. Sex Roles, 72, 521-535.

Wolfe G., \& Levant R.F. (2020). Treating masculinity: A commentary on the case of "Tommy." Pragmatic Case Studies in Psychotherapy, 16 (3), Article 4, 320-329. Available: http:/pcsp.libraries.rutgers.edu/ 